\title{
EXTENT AND DETERMINANTS OF COST OF ROAD TRAFFIC INJURIES IN AN INDIAN CITY
}

\author{
G. M. M. REDDY ${ }^{1}$, HIMANSHU NEGANDHI ${ }^{2}$, DALBIR SINGH ${ }^{3}$, AMARJEET J. SINGH $^{4}$
}

\section{ABSTRACT}

BACKGROUND: Studies aimed at estimating losses that are incurred as a result of road traffic injuries (RTIs), especially at the family level, are very limited. AIMS: To ascertain the direct and productivity costs of road traffic injuries and their determinants. SETTINGS AND DESIGN: This study was a cross-sectional survey of all the road traffic crashes recorded by traffic police during 2004 in Chandigarh, a modern planned city of north India. MATERIAL AND METHODS: All road traffic crashes recorded by the traffic police during the year 1st January to 31 st December 2004 were included in the study. The houses of all the victims were visited. The direct costs included the immediate medical costs (i.e., emergency and hospital care, follow-up care, medicines and appliances, doctor bills, etc.), and nonmedical costs (transportation, property damage cost, etc.). STATISTICAL ANALYSIS: Work productivity and activity questionnaire (WPAI-SHP), the health and labor questionnaire (HLQ) and Human Capital Method were used for estimating the productivity costs. Percentage, mean, standard deviation of the outcome parameters were calculated. RESULTS: Of the 121 crash victims listed, 95 agreed to participate in the study. The net direct costs incurred were Rs. 8,55,644 (\$19,991). The vehicle repair costs constituted more than half of such cost. Surgery, which was conducted in 28 cases, constituted $14.5 \%$ of the direct costs. The total productivity cost incurred was Rs. 8,06,24,530 (\$1,883,750). Costs incurred due to premature mortality constituted over $\mathbf{9 9 \%}$ of these productivity losses suffered by society. Lost wages due to the crash constituted less than $1 \%$ [Rs. 1,40,230 (\$3276)] of the total productivity loss. CONCLUSIONS: Road traffic injuries are a significant financial drag on the society. The productivity costs far outweigh the direct costs. Premature mortality, vehicle damage and medical costs constituted the major share of the cost of RTIs.

Key words: Direct cost, Human Capital Method, productivity cost, road traffic crashes

DOI: $10.4103 / 0019-5359.59988$

1Department of Community Medicine, School of Public Health, PGIMER, Chandigarh, ${ }^{2}$ Consultant, Public

Health Foundation of India, New Delhi, ${ }^{3}$ Department of Forensic Medicine, PGIMER, Chandigarh, ${ }^{4}$ Professor, Department of Community Medicine, School of Public Health, PGIMER, India

Correspondence:

Dr. Amarjeet J. Singh

School of Public Health, PGIMER, Chandigarh, India

E-mail: dramarminhas56@ rediffmail.com

\section{INTRODUCTION}

Over 1.2 million people die each year on the world's roads, and between 20 and 50 million suffer nonfatal injuries. ${ }^{[1]}$ Whereas such data on the extent of crashes are available, the studies aimed at estimating losses that are incurred as a result of injuries are limited due to the 
difficulty in linking the severity of the injury with the subsequent costs.

Projections regarding the probable costs of road traffic crashes available at the national and state level are arrived at using crude estimates. Most of these studies on costing of road traffic injuries are based on secondary data collection from insurance agencies and claim tribunals or from hospital bed occupancy. ${ }^{[2-7]}$ Studies at the family level attempting to uncover the actual costs suffered by the family as a result of the crash are very limited. Thus there exists a large gap in our knowledge regarding the costs suffered by the family. Against this background, this study was conducted with an objective to ascertain the direct and indirect costs of road traffic injuries and their determinants in an Indian city.

It is intended to provide policy makers with a city-level cost data, thus helping to frame a comprehensive road safety policy and counter the increasing trend of crashes.

\section{MATERIALS AND METHODS}

This cross-sectional study was done in Chandigarh, India, by a resident doctor (postgraduate student in community medicine) using a structured questionnaire. All road traffic crashes recorded by the traffic police during the year $1^{\text {st }}$ January to $31^{\text {st }}$ December 2004 were included in the study.

Road traffic injuries involving only the residents from outside Chandigarh but occurring within the geographical boundaries of the city and those involving native residents but occurring outside the geographical boundaries of Union
Territory, Chandigarh were excluded.

The current health status of the people involved in the listed injury cases was ascertained. For nonfatal cases, the victim was interviewed. If unavailable for questioning, the next of kin in the house was interviewed. For fatal crashes, the family member present in the house at the time of survey was interviewed. The outcome of the nonfatal injuries and the costs incurred due to injuries were noted.

After obtaining the socio-demographic data of the family of the victim, the victim or the family member was interviewed about the costs incurred after the road traffic injury. All relevant medical records and bills available were reviewed.

The direct costs included the immediate medical costs after the injury, i.e., transport, emergency and hospital care, follow-up care, medicines and appliances, doctor bills, hiring of domestic help, physiotherapy, rehabilitation, insurance, etc. Vehicular repair costs and the cost towards the purchase of an alternative vehicle made as a direct result of the crash were also noted. Cost of damage caused to public or government property was also estimated.

Work productivity and activity questionnaire (WPAI-SHP) and the health and labor questionnaire (HLQ) were utilized for the calculation of the productivity cost. ${ }^{[8,9]}$ Years of productive life lost, duration of the shortterm absenteeism from work and related loss of earnings were noted. Costs borne by the caregivers due to their absence from work were also noted. 
The cost of a premature death takes into consideration the age of the victim and the present earning status. The study involved a calculation of the years of potential employment for the person when compared to the mean retirement age of 60 years. The present earnings per month were then multiplied with the remaining months of service to yield an estimate of the cost of premature mortality. The calculation omits all individuals with no present earnings. It also excludes people in employment with age above 60 years. Work loss costs are estimated by counting the number of days absent from work and multiplying it by the daily income.

Informed consent was taken from the respondents. The research proposal was cleared by the Institute Ethics Committee before initiating the study. Epi2000 software was used for data analysis. Percentage, mean, standard deviation of the outcome parameters were calculated.

\section{RESULTS}

Overall, 148 crash episodes involving 298 persons have happened in the reporting year. One hundred seventy-seven cases involving nonresidents of the city were excluded. A total of 121 crash cases were listed. Majority (86; $71 \%$ ) of the victims were in the age group of 15 to 44 years. Sixty-eight $(56.2 \%)$ respondents were resident of urban areas of the city, 33 $(27.3 \%)$ were from rural areas and $20(16.5 \%)$ lived in slums. Response rate was $78.5 \%$, as 95 victims (including family members in lieu of victims who were unavailable due to the crash being fatal) agreed to participate in the study.
The majority $(67 ; 70.52 \%)$ did not receive any immediate help after the crash. Only 17 $(17.89 \%)$ victims received some sort of help immediately [from the witnessing public in 13 $(13.6 \%)$ cases, from co-victim in 4 cases]. In $11(11.5 \%)$ cases, the respondent did not know whether any immediate help was given or not.

In $58(61.1 \%)$ cases, police reached the site of crash in the presence of the victim. This could be due to the well-advertised traffic police helpline no. 1078 in the city newspapers and hoardings. In 24 cases, the police reached the site after the victim was taken to a doctor. In 13 cases, the respondent did not know about this.

The police vehicle was used for the transport of the crash victims to the hospital in about half of the cases in this study. In about a third of the cases, the witnessing public or the victims of the crashes used available resources and means of conveyance for carrying the victims/ themselves to the nearest doctor. During transport, no first aid or care was provided to the crash victims in 79 (83\%) cases. In $16(16.8 \%)$ cases, no such information was available.

In $68(71.57 \%)$ cases, the hospital was within $5 \mathrm{~km}$ of the site of the crash; and in $27(28.4 \%)$ cases, it was 5 to $10 \mathrm{~km}$ away. In 72 (75.7\%) cases, the victim was alive; in $23(24.2 \%)$ cases, the victim was declared dead on arrival at the hospital.

Our study also revealed that $38 \%$ of the crash victims brought to the hospital were in a condition serious enough to warrant a surgery. (Out of 72 alive on arrival at the hospital, 28 victims underwent surgery.) 
A major surgery was performed in 28 (29.4\%) cases (within 3 hours in 7 cases; within 24 hours in 19 cases; and in 2 cases, after 24 hours). Duration of stay at home due to crash was 3 days to 1 week in 7 cases; between 1 and 2 weeks, in 9 cases; and for more than 2 weeks, in 11 cases.

In about $25 \%$ of the cases, the survivors of the crashes took leave ranging up to 7 days from their occupation. In majority of the cases, social activities of the victims were restricted due to injury for a period of more than 1 week.

Nine patients said that they did not need any help at home. Only 1 patient needed assistance for more than 2 weeks. In 4 cases, a hired help was employed at home after the crash. In $24(25.2 \%)$ cases, no one was hired. On an average, 3.25 hours were spent by the hired help. In 2 cases, Rs. 800 was paid per month for the services provided. The maximum amount paid was Rs. 2000 per month (US $\$ 1=$ Rs. 42.8).

Table 1 shows the breakup of the direct costs into sub-categories. The total expenditure incurred was Rs. 8,55,644 (\$19,991). Medical costs and nonmedical costs constituted $43.6 \%$ and $53.4 \%$ of direct costs, respectively. More than half of the direct costs were attributed to vehicular repair, i.e., Rs. 4,77,300 $(\$ 11,151)$; the least amount, i.e., Rs. 4,569 (\$106), was spent on travel of the relatives from the place of residence to the hospital where the victims were being treated. Amount spent on purchase of medicines [Rs. 1,28,400 (\$3000)] was the highest contributor to the medical costs. Although surgery was performed on only 28 subjects out of the total 95 subjects contacted,
Table 1: Components of direct costs (in rupees)

\begin{tabular}{lccc}
\hline \multirow{2}{*}{$\begin{array}{l}\text { Cost } \\
\text { component }\end{array}$} & \multicolumn{3}{c}{ Cost $(n=95)$} \\
\cline { 2 - 4 } & Total & Mean $+S D$ & Median \\
\hline Medical costs & $(43.6 \%)$ & & \\
\hline Surgery & $1,28,000$ & $4,600+1,979$ & 4,500 \\
& $(\$ 2991)$ & $(\$ 107.5+46)$ & $(\$ 105)$ \\
Prostheses & 14,300 & $2,383+481$ & 2,450 \\
& $(\$ 334)$ & $(\$ 55+11)$ & $(\$ 57)$ \\
Lab & 89,925 & $1,635+1,335$ & 1,600 \\
& $(\$ 2,101)$ & $(\$ 38+31)$ & $(\$ 37)$ \\
Medicines & $1,28,400$ & $2,006+2,276$ & 1,000 \\
& $(\$ 3,000)$ & $(\$ 47+53)$ & $(\$ 23)$ \\
Hospital & 13,150 & $470+564$ & 300 \\
stay & $(\$ 307)$ & $(\$ 11+13)$ & $(\$ 7)$ \\
Nonmedical costs $(56.4 \%)$ & & \\
Vehicle & $4,77,300$ & $9,178+6,689$ & 8,000 \\
repair & $(\$ 11,152)$ & $(\$ 214+156)$ & $(\$ 187)$ \\
Travel & 4,569 & $57+36$ & 50 \\
Total & $(\$ 107)$ & $(\$ 1.3+0.8)$ & $(\$ 1.1)$ \\
\hline
\end{tabular}

it constituted a significant share (15\%) of the expenses (Rs. 1,28,000). The remaining portion of the medical costs comprised of hospital stay, amount spent on prostheses and laboratory expenses.

The majority of the productivity costs were incurred due to premature mortality of the crash victims. This constituted over $90 \%$ of the potential losses suffered by society Rs. 8, 06, $24,530(\$ 1,883,750)$. Lost wages due to the crash contributed Rs. $1,40,230(\$ 3,276)$ to the total productivity loss [Table 2].

\section{DISCUSSION}

Chandigarh is a modern planned city of north India with a population of 910,000 (2001 census). ${ }^{[10]}$ The city has a grid plan with near-straight roads throughout. The major roads have additional separate cycle paths for segregation of slow-moving traffic. As compared to other cities in India, the city has 
Table 2: Components of productivity costs (in rupees)

\begin{tabular}{lcccc}
\hline Cost component & \multicolumn{3}{c}{ Cost $(n=95)$} & Median \\
\cline { 2 - 5 } & Total & Mean $+S D$ & $15,00,000$ & $69,36,000 ; 90,000$ \\
\hline Premature & $8,04,79,200$ & $20,11,980+16,62,538$ & $(\$ 35,046)$ & $(\$ 162,056 ; 2,102)$ \\
mortality & $(\$ 1,880,355)$ & $(\$ 47,008+38,844)$ & 3,262 & 29,$155 ; 798$ \\
Lost wages & $1,40,230$ & $5,193+5,829$ & $(\$ 76.21)$ & $(\$ 681 ; 19)$ \\
& $(\$ 3276)$ & $(\$ 121+136)$ & 1,750 & 2,$800 ; 800$ \\
Housekeeping & 5,100 & $1,775+729$ & $(\$ 40.89)$ & $(\$ 65 ; 19)$ \\
& $(\$ 119)$ & $(\$ 41+17)$ & \\
Total & & $8,06,24,530(\$ 1,883,750)$ & \\
\hline
\end{tabular}

very few signal junctions (traffic), with a predominance of roundabouts at the junctions.

Overall, 148 crash episodes involving 298 persons have happened in the reporting year. A total of 121 crash cases involved the residents of the city and hence were eligible for enrolment in the study. The net direct costs incurred were Rs. 8,55,644 $(\$ 19,991)$. The total productivity cost incurred was Rs. $8,06,24,530$ $(\$ 1,883,750)$.

The crash rate was 16.2 per 100,000 . With more than 600,000 vehicles in the city, the rate of crashes was 0.24 per 1000 registered vehicles, which is lower than that in other Indian cities, i.e., 7.2 per 1000 registered vehicles. ${ }^{[10]}$ This difference may be due to better road conditions in Chandigarh. The presence of roundabouts may also be a factor for such difference as it decreases vehicular density at busy intersections while allowing for the smooth movement of traffic across the roads. Chandigarh also has the distinction of the highest per capita vehicle ownership in India ( $>2$ vehicles per capita). It is observed that in such a situation, the owner uses only one vehicle, while the other vehicle lies underutilized. These unused additional vehicles may inflate the denominator, thus affecting the calculations.
The case fatality rate (CFR) for the RTIs in the city was $70.52 \%$. It was exclusively based on crashes recorded by the police, which are more likely to be serious and potentially life threatening.

The productivity costs [Rs. $8,06,24,530$ $(\$ 1,883,750)]$ far outweighed the direct costs [Rs. 8,55,644 $(\$ 19,991)]$ in the study. Various studies conducted globally have proved that the productivity costs far outweigh the direct costs; cost estimates based on only direct costs, particularly only medical costs, can be grossly inadequate..$^{[11,12]}$

Costs due to road traffic crashes are affected by a variety of factors. Any factor that influences the earning capacity of an individual will result in an impact on the family and society in economic terms. The age group of 15 to 45 years is considered the most productive age group for any nation. An injury affecting someone from this age group will have more impact than that affecting a person outside this age group.

In our study also, this age group was most commonly involved in road traffic crashes $\mathbf{7 1 1 \%}$ of total cases). This predominance is evident in studies conducted all over the world. The high rate of crashes in this particular group 
illustrates the need for effective targeting of this age group for any intervention to significantly reduce the burden of road traffic crashes in the city.

Severity of injuries sustained during crashes affects direct cost (DC) as well as productivity cost (PC). In our study, the PC was significantly higher than the DC. PC depends upon the income and the number of life years lost. The net fatal-crash costs are usually higher than that the nonfatal ones. This is because the nonfatal crashes only involve the costs incurred for the treatment and the rehabilitation of the victim, and the cost of absence from work. In contrast, the fatal crashes contribute to the premature mortality costs, which are quite substantial and reflect the potential loss of earning due to the death. Thus, any factor that decreases severity of injury and reduces mortality will also improve survival. This will reduce the net costs incurred.

Similarly, the lag between the occurrence of road traffic crash and initiation of treatment influences the outcome consequent to the injury, thus affecting both DC and PC. The first hour after the crash is referred to as a golden hour because of the precious nature of this interval with regard to survival of the injured person and long-term prognosis of the injury. An appropriate intervention carried out early is one of the cornerstones of medical and surgical care. ${ }^{[13,14]}$ Prompt care would thus alter the mortality rates and significantly bring down the net costs. Our study shows that in less than a fifth of the cases reported, the victim had received some form of immediate help after the crash.
In our study, only a small percentage of crash victims were transported by specialized vehicles and received first aid during the transport. Latest WHO report on the status of global road safety showed that $76 \%$ of the 178 member countries have formal pre-hospital care system, but not all have a system in place wherein the victims are escorted to the hospital by trained paramedics in specialized vehicles, well equipped to handle life-threatening emergencies. ${ }^{[10]}$

The absence of provision of first aid during transport from the crash site to the hospital, as revealed in our study, shows that no attempts are made to provide this crucial care to the victims. Thus precious time, during which the patient probably needs prompt and utmost care, is lost. The reason could be the ignorance of the escorting person about the first aid to be provided. The police personnel are given some form of first aid training. This could be further strengthened by appropriate training by specialists, preferably in acute trauma care facilities.

The fact that more than one third of injury victims needed surgery represents a burden to be handled by the trauma care services due to the crashes. This will directly feed into the surgery costs, a component of the DC. Thus all the factors associated with a better utilization of the golden hour will have a beneficial effect in monetary terms, by cost reduction. ${ }^{[13,14]}$

Early surgery (in the first seven hours) was possible only in a quarter of the total surgeries performed, with nearly all victims operated within the first day. Early performance of a 
necessary surgery would have an impact on survival as well as the future rehabilitation of the victims. Any intervention which would ensure prompt transport of the victims in serious condition to the appropriate hospital (with requisite facilities) would decrease the economic burden due to the crashes.

Limitation of social activity of crash victims due to absence from work or less than full participation also feeds into the productivity losses suffered consequent upon injury.

Limitations of daily activities like bathing and using toilet were reported. In 11 cases, family members helped in bathing and toilet activities of the crash victim.

Head injuries contribute more to the crash costs than injuries to other sites of the body due to more chances of deaths as a result of brain trauma. Investigations like CT scan and procedures like neurosurgery are costlier than other surgical procedures. Thus injuries to sensitive body parts would influence the cost of immediate care. ${ }^{[15]}$ In our study, over half of the crash victims had head injury.

The available evidence shows that injuries can be a significant financial drag on the society, and outcomes and cost of road traffic crashes can vary remarkably even within a country. ${ }^{[16,17]}$ City-level data with a family perspective are vital in understanding the true economic burden of traffic crashes and making appropriate investment in the area of injury prevention. ${ }^{[18,19]}$ But taking only the economic burden as a proxy for the pain and suffering of crash victims and their family is debatable.

\section{CONCLUSION}

The net cost of road traffic crashes for Chandigarh city was Rs. 8,15,15,654 $(\$ 1,904,571)$ for 2004 . Productivity costs far outweighed the direct costs. A large share of the productivity costs belonged to premature mortality. Thus any investment for, and efforts at, primary prevention of injury, i.e., reducing the occurrence of road traffic crashes, and reducion of all factors that increase crashrelated mortality would help in reducing the costs associated with road traffic crashes.

\section{Strength of the study}

As against the usual data collection from secondary sources in most such studies, the present study was based on primary data collection at the family level.

\section{Limitations}

- There may be a recall bias since the reference period was 1 year.

- The investigator could not manage to obtain the figures for out-of-court settlement costs in cases in which they occurred because of the reluctance of the respondents to share such information .

- Results are based on cases recorded by the police. The milder cases and those not registered by the police might have been missed.

- Lack of information about the 26 nonparticipants could have resulted in either underestimation or overestimation of the costs, depending on the proportion of fatal accidents in cases of nonparticipants.

- The exclusion of 177 cases of crashes involving nonresidents occurring in the city 
could have resulted in underestimation of the costs to the city.

\section{Future research}

Studies focusing on house-to-house survey to collect community-based data on burden and cost of injuries may should be done.

\section{REFERENCES}

1. Global status report on road safety: Time for action. Geneva: World Health Organization; 2009.

2. Mohan D. The road ahead: Traffic injuries and fatalities in India. Final report. New Delhi: Transportation Research and Injury Prevention Programme, Indian Institute of Technology; 2004.

3. Bastida JL, Aguilar PS, González BD. The economic costs of traffic accidents in Spain. $J$ Trauma 2004;56:883-8.

4. van Beeck EF, van Roijen L, Mackenbach JP. Medical costs and economic production losses due to injuries in the Netherlands. J Trauma 1997;42:1116-23.

5. Natatrajan T. Costs of Road Crashes [dissertation]. Department of Traffic and Urban Engineering: College of Engineering, Guindy, Madras: 1980.

6. Road User Cost Study in India. Final Report. New Delhi: Central Road Research Institute; 1982.

7. Evaluation of Road Crash Costs: Research Digest. Indian Highways 2000;28:27-44.

8. Reilly MC, Zbrozek AS, Dukes EM. The validity and reproducibility of a work productivity and activity impairment instrument. Pharmacoeconomics 1993;4:353-65.

9. van Roijen L, Essink-Bot ML, Koopmanschap MA, Bonsel G, Rutten FF. Labor and health status in economic evaluation of health care: The Health and Labor Questionnaire. Int J Technol Assess
Health Care 1996;12:405-15.

10. Census of India 2001. Registrar General and Census Commissioner, India 2001.

11. Riewpaiboon A, Piyauthakit $P$, Chaikledkaew U. Economic burden of road traffic injuries: A micro costing approach. Southeast Asian J Trop Med Public Health 2008;39:1139-49.

12. Zaloshnja E, Miller T, Council F, Persaud B. Comprehensive and human capital crash costs by maximum police-reported injury severity within selected crash types. Annu Proc Assoc Adv Automot Med 2004;48:251-63.

13. Coats TJ, Davies G. Prehospital care for road traffic casualties. BMJ 2002;324:1135-8.

14. Bunn F, Kwan I, Roberts I, Wentz R. Effectiveness of prehospital trauma care. Report to the World Health Organization Prehospital Care Steering Committee. Geneva: WHO, 2001.

15. Singh M, Vaishya S, Gupta S, Mehta VS. Economics of head injuries. Neurol India 2006;54:78-80.

16. Olukoga, Abiodun. Cost analysis of road traffic crashes in South Africa. Int J Injury Control Safety Promotion 2004;11:59-62.

17. Connelly LB, Supangan R. The economic costs of road traffic crashes: Australia, states and territories. Accident Analysis Prev 2006;38: 1087-93.

18. Hijar M, Arredondo A, Carrillo C, Solórzano L. Road traffic injuries in an urban area in Mexico: An epidemiological and cost analysis. Accid Anal Prev 2004;36:37-42.

19. García-Altés A, Pérez K. The economic cost of road traffic crashes in an urban setting. Inj Prev 2007;13:65-8.

Source of Support: Nil. Conflict of Interest: None declared. 